\title{
Article
}

\section{Cardiometabolic Disorders and the Risk of Critical COVID-19 as Compared to Influenza Pneumonia}

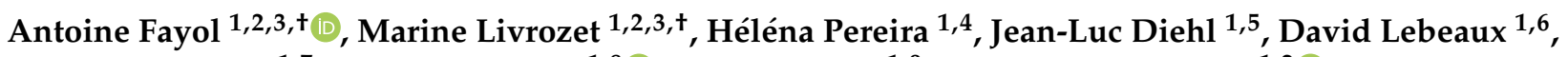

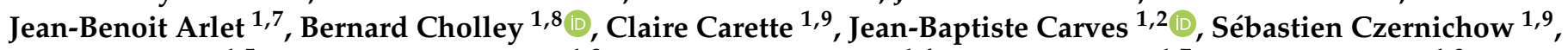 \\ Caroline Hauw ${ }^{1,5}$, Sophie-Rym Hamada ${ }^{1,8}$, Anne-Sophie Jannot ${ }^{1,4}$, Geoffroy Volle 1,7, Nihar Masurkar ${ }^{1,3}$, \\ Tristan Mirault 1,3,10 ${ }^{-}$, Benjamin Planquette ${ }^{1,11}$, Olivier Sanchez ${ }^{1,11}$, Gilles Châtellier ${ }^{1,4}$, Michel Azizi ${ }^{1,2,12}$ and \\ Jean-Sébastien Hulot $1,2,3, * \mathbb{D}$
}

check for updates

Citation: Fayol, A.; Livrozet, M.; Pereira, H.; Diehl, J.-L.; Lebeaux, D.; Arlet, J.-B.; Cholley, B.; Carette, C.; Carves, J.-B.; Czernichow, S.; et al. Cardiometabolic Disorders and the Risk of Critical COVID-19 as Compared to Influenza Pneumonia. J. Clin. Med. 2021, 10, 4618. https:// doi.org/10.3390/jcm10194618

Academic Editor: Taulant Muka

Received: 27 August 2021

Accepted: 4 October 2021

Published: 8 October 2021

Publisher's Note: MDPI stays neutral with regard to jurisdictional claims in published maps and institutional affiliations.

Copyright: (c) 2021 by the authors. Licensee MDPI, Basel, Switzerland. This article is an open access article distributed under the terms and conditions of the Creative Commons Attribution (CC BY) license (https:// creativecommons.org/licenses/by/ $4.0 /)$.
1 Université de Paris, F-75006 Paris, France; antoine.fayol@aphp.fr (A.F.); marine.livrozet@aphp.fr (M.L.); helena.pereira@aphp.fr (H.P.); jean-luc.diehl@aphp.fr (J.-L.D.); david.lebeaux@aphp.fr (D.L.); jean-benoit.arlet@aphp.fr (J.-B.A.); bernard.cholley@aphp.fr (B.C.); claire.carette@aphp.fr (C.C.); jean-baptiste.carves@aphp.fr (J.-B.C.); sebastien.czernichow@aphp.fr (S.C.); caroline.hauw-berlemont@aphp.fr (C.H.); sophie.hamada@aphp.fr (S.-R.H.); annesophie.jannot@aphp.fr (A.-S.J.); geoffroy.volle@aphp.fr (G.V.); nihar.m1990@gmail.com (N.M.); tristan.mirault@aphp.fr (T.M.); benjamin.planquette@aphp.fr (B.P.); olivier.sanchez@aphp.fr (O.S.); gilles.chatellier@aphp.fr (G.C.); michel.azizi@aphp.fr (M.A.)

2 CIC1418 and DMU CARTE, Assistance Publique Hôpitaux de Paris (AP-HP), Hôpital Européen Georges-Pompidou, F-75015 Paris, France

3 INSERM, Paris Cardiovascular Research Center, PARCC, UMR970, F-75015 Paris, France

4 Clinical and Epidemiological Unit, AP-HP, Hôpital Européen Georges-Pompidou, F-75015 Paris, France

5 Medical Intensive Care Unit, AP-HP, Hôpital Européen Georges-Pompidou, F-75015 Paris, France

6 Service de Microbiologie, Unité Mobile d'Infectiologie, AP-HP, Hôpital Européen Georges-Pompidou, F-75015 Paris, France

7 Internal Medicine Department, Sickle Cell Referral Center, AP-HP, Hôpital Européen Georges-Pompidou, F-75015 Paris, France

8 Department of Anesthesia and Intensive Care, AP-HP, Hôpital Européen Georges-Pompidou, F-75015 Paris, France

9 Service de Nutrition, Centre Spécialisé Obésité, AP-HP, Hôpital Européen Georges-Pompidou, F-75015 Paris, France

10 Médecine Vasculaire HyperVASC and DMU CARTE, AP-HP, Hôpital Européen Georges-Pompidou, F-75015 Paris, France

11 Service de Pneumologie et Soins Intensifs, AP-HP, INSERM UMR-S 1140, Hôpital Européen Georges-Pompidou, F-75015 Paris, France

12 Hypertension Unit and DMU CARTE, AP-HP, Hôpital Européen Georges-Pompidou, F-75015 Paris, France

* Correspondence: jean-sebastien.hulot@aphp.fr

+ These authors contributed equally to this work.

Abstract: We aimed to compare the influence of cardiometabolic disorders on the incidence of severe COVID-19 vs. non-COVID pneumonia. We included all consecutive patients admitted with SARSCoV-2-positive pneumonia between 12 March 2020 and 1 April 2020 and compared them to patients with influenza pneumonia hospitalized between December 2017 and December 2019 at the same tertiary hospital in Paris. Patients with COVID-19 were significantly younger and more frequently male. In the analysis adjusted for age and sex, patients with COVID-19 were more likely to be obese (adjOR: 2.25; 95\% CI 1.24-4.09; $p=0.0076$ ) and receive diuretics (adjOR: 2.13; 95\% CI 1.12-4.03; $p=0.021$ ) but were less likely to be smokers (adjOR: 0.40; 95\% CI 0.24-0.64; $p=0.0002$ ), have COPD (adjOR: $0.25 ; 95 \%$ CI 0.11-0.56; $p=0.0008$ ), or have a previous or active cancer diagnosis (adjOR: 0.54, $95 \%$ CI $0.32-0.91 ; p=0.020)$. The rate of ICU admission was significantly higher in patients with COVID-19 (32.4\% vs. 5.2\% $p<0.0001$ ). Obesity was significantly associated with the risk of direct ICU admission in patients with COVID-19 but not in patients with influenza pneumonia. Likewise, pre-existing hypertension was significantly associated with mortality in patients with COVID-19 but not in patients with influenza pneumonia. Cardiometabolic disorders differentially influenced the risk of presenting with severe COVID-19 or influenza pneumonia. 
Keywords: COVID-19; seasonal influenza; cardiovascular risk factors; obesity; hypertension

\section{Introduction}

Severe acute respiratory syndrome coronavirus-2 (SARS-CoV-2) is the causative agent of COVID-19, an infection that primarily targets the lungs [1]. The risk of developing severe or critical forms of COVID-19 pneumonia is influenced by underlying conditions. Notably, cardiac, vascular, and metabolic disorders including hypertension, coronary heart disease, diabetes, and obesity are highly prevalent among patients with severe COVID-19 [2-6], and mortality rates tend to be higher in those with cardiometabolic comorbidities $[7,8]$. In general, severe COVID-19 is more prevalent in patients aged greater than 50 years [2,3,8,9], a population that largely overlaps with those most at risk for or already having a history of hypertension, diabetes, or other cardiometabolic diseases [10].

In the general population, age and cardiometabolic diseases are also independently associated with the occurrence of non-COVID pneumonia [11]. Obesity has been considered an independent predisposing factor for severe H1N1 pulmonary infection [12]. Further, patients with known cardiovascular diseases are at higher risk of severe outcomes when suffering from lower respiratory tract infections, especially those related to influenza [13]. RAS blockers have been shown to improve pneumonia-related outcomes even in patients with viral [14,15] and influenza pneumonia [16].

Given the world-wide dissemination of the COVID-19 pandemic, further evidence is warranted for the appropriate management of patients with cardiometabolic disorders [17]. A limited number of studies have directly compared the factors associated with the risk of presenting severe or fatal COVID-19 with those found in patients with severe influenza pneumonia [18,19]. The aim of the present study was to compare the characteristics and prognoses of patients hospitalized for COVID-19 in 2020 with patients hospitalized for influenza during the 2018-2019 season.

\section{Materials and Methods}

\subsection{Study Design and Participants}

We conducted a single-center observational study on the first 253 consecutive adult patients ( $\geq 18$ years) with laboratory-confirmed COVID-19 infection admitted to the Hôpital Européen Georges Pompidou (HEGP) in Paris, France, between 12 March and 1 April 2020 and further hospitalized for more than $24 \mathrm{~h}$ owing to severe or critical pneumonia, as previously defined in [7]. Confirmed COVID-19 cases were defined by positive realtime reverse-transcriptase polymerase chain reaction (RT-PCR) results for SARS-CoV-2 performed on nasopharyngeal or oropharyngeal swab specimens, bronchoalveolar lavage samples, or bronchial aspirates. COVID-19 pneumonia cases were confirmed by (i) a peripheral oxygen saturation level $\left(\mathrm{SpO}_{2}\right) \leq 94 \%$ as measured by a pulse oximeter device and/or (ii) an abnormal chest computed tomography (CT) scan with radiological patterns consistent with COVID-19 [20]. Fourteen-day mortality was monitored for all included patients.

To determine if associated characteristics were specific to patients with COVID-19, we formed a second retrospective cohort of 153 consecutive adult patients ( $\geq 18$ years) admitted to the same hospital (HEGP, Paris, France) with seasonal influenza respiratory tract infections and requiring hospitalization because of hypoxia with an $\mathrm{SpO}_{2} \leq 94 \%$, the same criteria used for determining pneumonia in COVID-19 patients. We identified these patients with severe or critical influenza respiratory infection in the immediate period preceding the advent of the COVID-19 epidemic in the Paris area, i.e., between 8 December 2017 and 17 December 2019, using the medico-administrative data of the hospital. Patients were included if their hospital stay was classified in the influenza group of the French Diagnostic Related Group (DRG) system. 


\subsection{Data Collection}

Demographic, clinical, comorbidity, treatment, and outcome data for patients with COVID-19 were extracted from the electronic medical records collected in a standardized data collection form implemented on 11 March 2020 in the Clinical Data Warehouse (CDW) of the HEGP. The dedicated medical records were stored on an $\mathrm{i} 2 \mathrm{~b} 2$ platform in the CDW along with all other hospital health records. Demographic, clinical, treatment, and outcome data for patients with influenza respiratory tract infections were also extracted from the CDW of the HEGP. All data were separately verified by two investigators separately (A.F. and M.L.) and discordances in interpretation were reconciled by a third investigator (J.S.H.).

\subsection{Definitions}

The intensive care unit (ICU) patients with COVID-19 were defined by hospitalization in one of the dedicated ICU units representing 110 ICU beds as of 1 April 2020. Indication of ICU admission was based on the presence of acute respiratory distress syndrome (ARDS) defined according to the Berlin Definition [21] and requiring high-flow nasal oxygen therapy, non-invasive mechanical ventilation, or invasive mechanical ventilation. Hospitalization in non-ICU units (representing 158 beds as of 1 April 2020) was determined when patients required only nasal, low-flow oxygen administration and standard medical monitoring. Direct admission to the ICU was defined as patients requiring immediate transfer or transfer within $24 \mathrm{~h}$ to an ICU (referred as critical COVID-19). Secondary admission to the ICU was defined for non-ICU patients who required ICU admission $>24 \mathrm{~h}$ after their initial admission. $\mathrm{SpO}_{2}$ was measured upon admission, usually in the emergency room and before oxygen administration, when possible. Body mass index (BMI) was measured at hospital admission, and obesity was defined as a BMI $\geq 30 \mathrm{~kg} / \mathrm{m}^{2}$.

Medical history and smoking status were collected at hospital admission as reported by the patient (or by the accompanying person if the patient was unable to communicate), or directly from the electronic medical record for those who had a previous admission in our institution. Information on the following variables was extracted: age, sex, any history of cardiovascular or metabolic disease (defined by pre-existing hypertension, diabetes, hypercholesterolemia, ischemic heart disease, or atrial fibrillation), pulmonary disease (chronic obstructive pulmonary disease (COPD) or asthma), chronic kidney disease, hypothyroidism, or malignancy (excluding non-melanoma skin malignancy). These comorbidities were defined according to the current French or European guidelines. Data on chronic kidney disease (estimated glomerular filtration rate (eGFR) by MDRD $\leq$ $45 \mathrm{~mL} \mathrm{~min}-1.73 \mathrm{~m}^{-2}$, grade IIIlb) and hypothyroidism were retrieved from past medical histories or laboratory measurements performed prior to hospitalization. An active cancer case was defined as a patient treated for cancer, and a previous cancer case was defined as a patient cured of a malignant disease. Smoking status was defined as "never smoker", "active smoker", or "previous smoker (smoking cessation > 3 months)". Cardiovascular treatments were retrieved from the patient's prescriptions at admission, including RAS blockers, beta-blockers, diuretics, calcium channel blockers, and statins.

\subsection{Statistical Analysis}

Continuous variables were presented as means \pm standard deviation (SD) while categorical variables are shown as frequency (\%) unless otherwise stated. Continuous data were compared using Student's $t$-test and categorical variables were compared using the $\chi^{2}$ or Fisher's exact test, as appropriate.

Risk factors associated with critical COVID-19 on admission, as determined by the need for direct ICU hospitalization, were analyzed using odds ratios (ORs) and 95\% confidence intervals (CIs) estimated for each variable using a logistic regression model adjusted for age and sex. Significance was assessed with the Wald test. Variables with a value of $p<0.25$ were subjected to a multivariate logistic regression analysis to simultaneously examine their independent effect. The final age- and sex-forced model was obtained through 
stepwise deletion of variables until all the predictors left had a $\mathrm{p}$ value less than 0.05 . BMI or obesity (defined as BMI $\geq 30 \mathrm{~kg} / \mathrm{m}^{2}$ ) were tested in separate models.

Overall survival was analyzed with a two-sided log-rank test, and hazard ratios (HRs) and two-sided $95 \%$ CI values were calculated using the Cox proportional hazard model. The proportional hazard assumption was assessed by testing the interaction between covariates and time. Sex and age (dichotomized at the median value) were also forced into the Cox model.

The comparison of characteristics between patients with COVID-19 and influenza respiratory infections was performed using an OR and a 95\% CI estimated for each variable using a sex- and age-adjusted logistic regression model. Any characteristic with an OR $>1$ was more frequently observed in COVID-19 patients than in influenza patients. Significance was assessed by the Wald test.

All statistical analyses were performed using SAS (version 9.4; SAS Institute, Cary, NC, USA). Two-sided $p$ values $\leq 0.05$ were considered statistically significant.

\section{Results}

\subsection{Patients with COVID-19}

\subsubsection{Baseline Characteristics}

Between 12 March and 1 April 2020, 253 patients were hospitalized at the HEGP with confirmed SARS-Cov-2-positive pneumonia. Their mean age was $64.7 \pm 16.1$ years, and 174 patients $(68.8 \%$ ) were male (Table 1$)$. A total of 82 patients were critical and required immediate or within $24 \mathrm{~h}$ transfer to an ICU. The remaining 171 patients with COVID-19 required non-ICU hospitalization at admission (Figure 1). The mean delay between the onset of symptoms and hospitalization was $6.9 \pm 3.4$ days, and there was no significant difference between the groups ( $7.2 \pm 3.2$ vs. $6.8 \pm 3.5$ days; $p=0.44$ for ICU versus non-ICU, respectively).

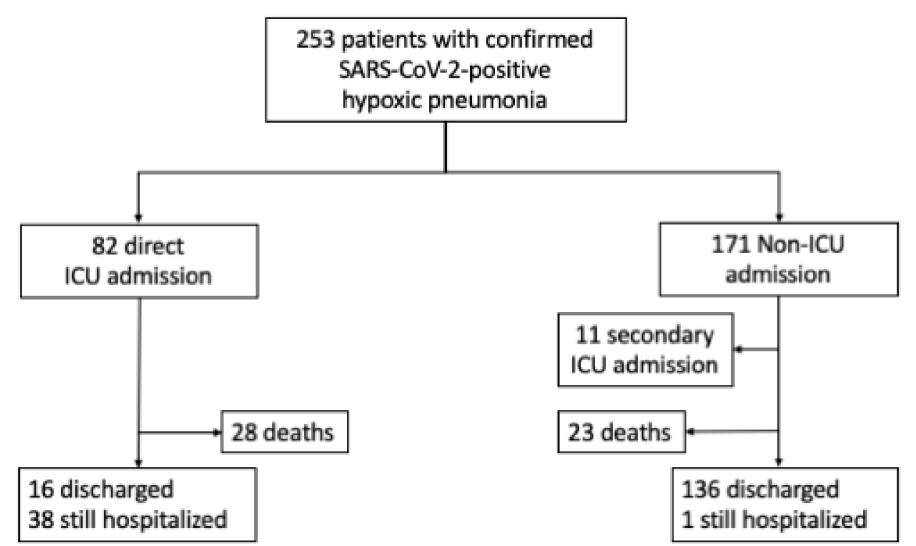

Figure 1. Flow diagram of patients with COVID-19 included in the study and outcomes during the 14-day follow up. 
Table 1. Demographic and clinical characteristics, comorbidities, and cardiovascular therapies of COVID-19 patients requiring admission to ICU and non-ICU patients hospitalized between 12 March 2020 and 1 April 2020 and of influenza respiratory infection patients requiring hospitalization (2017-2019). Reported data are at hospital admission at Hôpital Européen Georges Pompidou in Paris, France.

\begin{tabular}{|c|c|c|c|c|}
\hline & \multicolumn{3}{|c|}{ COVID-19 Group } & \multirow{2}{*}{$\begin{array}{c}\text { Influenza Group } \\
\begin{array}{c}\text { Overall } \\
(n=153)\end{array}\end{array}$} \\
\hline & $\begin{array}{c}\text { ICU } \\
(n=82)\end{array}$ & $\begin{array}{l}\text { Non-ICU } \\
(n=171)\end{array}$ & $\begin{array}{l}\text { Overall } \\
(n=253)\end{array}$ & \\
\hline \multicolumn{5}{|l|}{$\begin{array}{l}\text { Demographic and clinical } \\
\text { characteristics }\end{array}$} \\
\hline Mean age (years) & $61.2(11.4)$ & $66.4(17.7)$ & $64.7(16.1)$ & $69.8(19.9)$ \\
\hline $\begin{array}{c}\text { Sex } \\
\text { Male } \\
\text { Female }\end{array}$ & $\begin{array}{l}65(79.3 \%) \\
17(20.7 \%)\end{array}$ & $\begin{array}{l}109(63.7 \%) \\
62(36.3 \%)\end{array}$ & $\begin{array}{l}174(68.8 \%) \\
79(31.2 \%)\end{array}$ & $\begin{array}{l}79(51.6 \%) \\
74(48.4 \%)\end{array}$ \\
\hline Body mass index $\left(\mathrm{kg} / \mathrm{m}^{2}\right)$ & $29.7(5.8)$ & $26.0(4.4)$ & $27.4(5.2)$ & $24.0(5.3)$ \\
\hline Mean $\mathrm{SpO}_{2}(\%)$ & $87.8(8.8)$ & $94.4(4.1)$ & $92.3(6.8)$ & $93.8(5.2)$ \\
\hline \multicolumn{5}{|l|}{$\begin{array}{c}\text { Cardiometabolic diseases and } \\
\text { risk factors }\end{array}$} \\
\hline \multirow{3}{*}{$\begin{array}{c}\text { Hypertension } \\
\text { On-treatment } \\
\text { Number of medications * }\end{array}$} & $39(47.6 \%)$ & $80(46.8 \%)$ & $119(47.0 \%)$ & $70(45.8 \%)$ \\
\hline & $\begin{array}{c}35 / 39 \\
(89.7 \%)\end{array}$ & $\begin{array}{l}75 / 80 \\
(94.9 \%)\end{array}$ & $110 / 119(93.2 \%)$ & $\begin{array}{c}67 / 70 \\
(95.7 \%)\end{array}$ \\
\hline & $2(1-5)$ & $2(1-6)$ & $2(1-6)$ & $1(1-4)$ \\
\hline Type 2 diabetes & $23(28.0 \%)$ & $28(16.4 \%)$ & $51(20.2 \%)$ & $28(18.3 \%)$ \\
\hline Obesity (BMI $\geq 30$ kg/m²) & $34 / 82(41.5 \%)$ & $\begin{array}{l}30 / 139 \\
(21.2 \%)\end{array}$ & $64 / 221(29.0 \%)$ & 18/121 (14.9\%) \\
\hline Current or previous smoker & $15 / 77(19.5 \%)$ & $\begin{array}{l}42 / 151 \\
(26.1 \%) \\
\end{array}$ & $57 / 228(23.9 \%)$ & $52 / 123(42.3 \%)$ \\
\hline Hypercholesterolemia & $18(22.2 \%)$ & $47(27.5 \%)$ & $65(25.8 \%)$ & $52(34.0 \%)$ \\
\hline Ischaemic heart disease & $7(8.5 \%)$ & $19(11.1 \%)$ & $26(10.3 \%)$ & $24(15.7 \%)$ \\
\hline Atrial fibrillation & $4(4.9 \%)$ & $21(12.3 \%)$ & $25(9.9 \%)$ & $26(17.0 \%)$ \\
\hline Chronic kidney disease & $4(4.9 \%)$ & $19(11.1 \%)$ & $23(9.1 \%)$ & $22(14.4 \%)$ \\
\hline \multicolumn{5}{|l|}{ History of other comorbidities } \\
\hline Asthma & $6(7.3 \%)$ & $10(5.8 \%)$ & $16(6.3 \%)$ & $16(10.5 \%)$ \\
\hline COPD & $1(1.2 \%)$ & $8(4.7 \%)$ & $9(3.6 \%)$ & $22(14.4 \%)$ \\
\hline Hypothyroidism & $5(6.1 \%)$ & $9(5.3 \%)$ & $14(5.5 \%)$ & $17(11.1 \%)$ \\
\hline Active or previous cancer & $4(4.9 \%)$ & $34(19.9 \%)$ & $38(15.0 \%)$ & $43(28.1 \%)$ \\
\hline \multicolumn{5}{|l|}{$\begin{array}{l}\text { Cardiovascular therapies at entry } \\
\text { among all patients }\end{array}$} \\
\hline ACEi & $10(12.2 \%)$ & $14(8.2 \%)$ & $24(9.5 \%)$ & $20(13.1 \%)$ \\
\hline ARB & $21(25.6 \%)$ & $35(20.5 \%)$ & $56(22.2 \%)$ & $26(17.0 \%)$ \\
\hline ACEi or ARB & $31(37.8 \%)$ & $49(28.8 \%)$ & $80(31.7 \%)$ & $45(29.4 \%)$ \\
\hline Diuretics & $17(20.7 \%)$ & $29(16.5 \%)$ & $45(17.9 \%)$ & $15(9.8 \%)$ \\
\hline Beta-blockers & $7(8.5 \%)$ & $26(15.3 \%)$ & $33(13.1 \%)$ & $13(8.5 \%)$ \\
\hline Calcium channel blockers & $16(19.5 \%)$ & $33(19.4 \%)$ & $49(19.4 \%)$ & $27(17.6 \%)$ \\
\hline Statins & $16(19.5 \%)$ & $42(24.7 \%)$ & $58(23.0 \%)$ & $47(30.9 \%)$ \\
\hline
\end{tabular}

Data are expressed as mean (SD) or $n(\%) . *$ : median (range) ICU: intensive care unit; BMI: body mass index; COPD: chronic obstructive pulmonary disease; ACEi: angiotensin-converting enzyme inhibitors; ARB: angiotensin II receptor blocker; $\mathrm{SpO}_{2}$ : peripheral oxygen saturation. 


\subsubsection{Risk of ICU Admission}

In comparison with the non-ICU patients with COVID-19, those in the ICU were predominantly male $(79.3 \%$ vs. $63.7 \% ; p=0.013)$ and significantly younger $(61.2 \pm 11.4 \mathrm{vs}$. $66.4 \pm 17.7$ years; $p=0.016$ ) (Table 1 ). After adjusting for age and sex, significant differences were noted in cardiometabolic comorbidities between both groups (Table 2). In comparison with the non-ICU patients, those in the ICU had higher BMIs (adjusted odds ratio [adjOR]: $1.15 ; 95 \%$ CI 1.08 to $1.23 ; p<0.0001$ ) and, therefore, were more likely to be obese (adjOR: 2.56; $95 \%$ CI 1.37 to $4.79 ; p=0.0031$ ) or to have type 2 diabetes mellitus (adjOR: $2.11 ; 95 \%$ CI 1.10 to $4.05 ; p=0.024)$. On the contrary, the ICU patients were less likely to have had a previous or active cancer diagnosis (adjOR: $0.25 ; 95 \%$ CI 0.08 to $0.74 ; p=0.013$ ). No significant differences were observed between the two groups for other cardiovascular diseases including having a history of hypertension (adjOR: 1.37; 95\% CI 0.75 to 2.48; $p=0.30$ ) or ischemic heart disease (adjOR: 0.86 ; $95 \%$ CI 0.33 to $2.25 ; p=0.76$ ). Moreover, no significant imbalance was noted in ongoing cardiovascular treatments at entry between these groups (Table 2). In the multivariate analysis with age and sex forced into the model, obesity (BMI $\geq 30 \mathrm{~kg} / \mathrm{m}^{2}$ ) was the only cardiometabolic disorder independently associated with the risk of presenting critical COVID-19 that required direct ICU admission (adjOR: 2.56 ; $95 \%$ CI $1.37-4.79 ; p=0.0031)$. This result was consistent with that of additional sensitivity analyses that excluded patients with secondary admission to the ICU $(n=11)$ or included patients with relative contraindications for ICU admission (age $>80$ years or patients with cancer, $n=67$ ).

\subsubsection{Mortality Rates and Predictors}

After a 14-day follow-up, 51 deaths (20.1\%) occurred during hospitalization including $28(34.1 \%)$ deaths in ICU patients and $23(13.4 \%)$ in non-ICU patients (adjusted HR (adjHR): $3.09 ; 95 \%$ CI 1.76 to $5.42 ; p<0.0001$ ). In the multivariate analysis with age and sex forced into the model, the risk of death was higher only among patients with a history of hypertension (adjHR: 2.22; 95\% CI 1.20-4.10; $p=0.0111$ ), which was the only factor independently associated with early mortality.

\subsection{Comparison between Patients with COVID-19 and Influenza Respiratory Infection}

From 8 December 2017 to 17 December 2019, a total of 153 patients with influenza pneumonia were hospitalized at our institution (Table 1). The rate of ICU admission among these patients was much lower than that in patients with COVID-19 $(5.2 \%$ vs. $32.4 \%$, $p<0.0001)$. Patients with influenza were significantly older than those with COVID-19 and showed an equal distribution of male and female patients (Table 1). The proportion of patients with pre-existing hypertension or on antihypertensive medication was similar between the two groups, but the median (range) number of medications at entry was lower in patients with influenza than in those with COVID-19 (1 (1-4) versus 2 (1-6)). In the analysis adjusted for age and sex, patients with COVID-19 were more likely to be obese (adjOR: 2.25; 95\% CI 1.24 to $4.09 ; p=0.0076$ ) and to receive diuretics (mainly $(86.7 \%)$ hydrochlorothiazide; adjOR: 2.13 ; $95 \%$ CI 1.12 to $4.03 ; p=0.021)$ but were less likely to be smokers (adjOR: $0.40 ; 95 \%$ CI 0.24 to $0.64 ; p=0.0002$ ), to have COPD (adjOR: $0.25 ; 95 \%$ CI 0.11 to $0.56 ; p=0.0008$ ), or have had a previous or active cancer diagnosis (adjOR: $0.54,95 \%$ CI 0.32 to $0.91 ; p=0.020$ ) (Table 3 and Figure 2A). Analysis restricted to non-ICU patients gave comparable effect sizes, although some associations were no longer significant owing to the smaller sample size (Figure 2B). Similar results were found when the analysis was restricted to patients with influenza hospitalized in 2019, the closest period to the COVID-19 epidemic. 
Table 2. Risk factors of COVID-19 severity among hospitalized patients with COVID-19 as determined from the need for ICU admission.

\begin{tabular}{|c|c|c|}
\hline & Adjusted * OR (95\% CI) & $p$ Value \\
\hline \multicolumn{3}{|c|}{ Demographic and clinical presentation } \\
\hline BMI (per $1 \mathrm{~kg} / \mathrm{m}^{2}$ increase) & $1.15(1.08-1.23)$ & $<0.0001$ \\
\hline Mean $\mathrm{SpO}_{2}$ (per $1 \%$ increase) & $0.83(0.77-0.88)$ & $<0.0001$ \\
\hline \multicolumn{3}{|c|}{ Cardiometabolic diseases and risk factors } \\
\hline Hypertension & $1.37(0.75-2.48)$ & 0.30 \\
\hline Type 2 diabetes & $2.11(1.10-4.05)$ & 0.024 \\
\hline Obesity $\left(\mathrm{BMI} \geq 30 \mathrm{~kg} / \mathrm{m}^{2}\right)$ & $2.56(1.37-4.79)$ & 0.0031 \\
\hline Current or previous smoker & $0.74(0.37-1.48)$ & 0.39 \\
\hline Hypercholesterolemia & $0.85(0.44-1.63)$ & 0.62 \\
\hline Ischemic heart disease & $0.86(0.33-2.25)$ & 0.76 \\
\hline Atrial fibrillation & $0.41(0.13-1.26)$ & 0.12 \\
\hline Chronic kidney disease & $0.43(0.14-1.33)$ & 0.14 \\
\hline \multicolumn{3}{|l|}{ History of other comorbidities } \\
\hline Asthma & $1.24(0.42-3.66)$ & 0.70 \\
\hline COPD & $0.31(0.04-2.57)$ & 0.28 \\
\hline Hypothyroidism & $1.58(0.49-5.15)$ & 0.44 \\
\hline Active or previous cancer & $0.25(0.08-0.74)$ & 0.013 \\
\hline \multicolumn{3}{|l|}{ Cardiovascular therapies at entry } \\
\hline ACEi & $1.64(0.68-3.98)$ & 0.27 \\
\hline $\mathrm{ARB}$ & $1.57(0.81-3.06)$ & 0.18 \\
\hline ACEi or ARB & $1.83(0.99-3.37)$ & 0.053 \\
\hline Diuretics & $1.42(0.71-2.84)$ & 0.32 \\
\hline Beta-blockers & $0.53(0.21-1.29)$ & 0.16 \\
\hline Calcium channel blockers & $1.08(0.54-2.15)$ & 0.82 \\
\hline Statins & $0.84(0.43-1.64)$ & 0.60 \\
\hline
\end{tabular}

ICU: intensive care unit; OR: odds ratio; BMI: body mass index; COPD: chronic obstructive pulmonary disease; ACEi: angiotensin-converting enzyme inhibitors; $\mathrm{ARB}$ : angiotensin II receptor blocker; $\mathrm{SpO}_{2}$ : peripheral oxygen saturation; $\mathrm{CI}$ : confidence interval * $\mathrm{OR}$ values are adjusted for sex and age. $\mathrm{OR}>1$ indicates that the characteristic was more frequently observed in COVID-19 patients requiring ICU hospitalization than in other hospitalized COVID-19 patients. Bold: subtitle. 
Table 3. Comparison of characteristics between patients hospitalized with COVID-19 and influenza.

\begin{tabular}{|c|c|c|}
\hline & Adjusted * OR (95\% CI) & $p$ Value \\
\hline \multicolumn{3}{|c|}{ Demographic and clinical presentation } \\
\hline BMI (per $1 \mathrm{~kg} / \mathrm{m}^{2}$ increase) & $1.14(1.08-1.19)$ & $<0.0001$ \\
\hline Mean $\mathrm{SpO}_{2}$ (per 1\% increase) & $0.96(0.92-1.00)$ & 0.037 \\
\hline \multicolumn{3}{|c|}{ Cardiometabolic diseases and risk factors } \\
\hline Hypertension & $1.24(0.80-1.93)$ & 0.33 \\
\hline Type 2 diabetes & $1.12(0.66-1.90)$ & 0.67 \\
\hline Obesity $\left(\mathrm{BMI} \geq 30 \mathrm{~kg} / \mathrm{m}^{2}\right)$ & $2.25(1.24-4.09)$ & 0.0076 \\
\hline Current or previous smoker & $0.40(0.24-0.64)$ & 0.0002 \\
\hline Hypercholesterolemia & $0.69(0.44-1.10)$ & 0.12 \\
\hline Ischemic heart disease & $0.59(0.31-1.12)$ & 0.11 \\
\hline Atrial fibrillation & $0.58(0.31-1.08)$ & 0.08 \\
\hline Chronic kidney disease & $0.54(0.28-1.02)$ & 0.06 \\
\hline \multicolumn{3}{|l|}{ History of other comorbidities } \\
\hline Asthma & $0.53(0.25-1.14)$ & 0.10 \\
\hline COPD & $0.25(0.11-0.56)$ & 0.0008 \\
\hline Hypothyroidism & $0.59(0.28-1.26)$ & 0.17 \\
\hline Active or previous cancer & $0.54(0.32-0.91)$ & 0.020 \\
\hline \multicolumn{3}{|l|}{ Cardiovascular therapies at entry } \\
\hline $\mathrm{ACEi}$ & $0.70(0.37-1.33)$ & 0.28 \\
\hline ARB & $1.57(0.92-2.69)$ & 0.10 \\
\hline $\mathrm{ACEi}$ or $\mathrm{ARB}$ & $1.21(0.76-1.91)$ & 0.42 \\
\hline Diuretics & $2.13(1.12-4.03)$ & 0.021 \\
\hline Beta-blockers & $1.70(0.85-3.41)$ & 0.13 \\
\hline Calcium channel blockers & $1.19(0.70-2.04)$ & 0.52 \\
\hline Statins & $0.70(0.44-1.12)$ & 0.13 \\
\hline
\end{tabular}

OR: odds ratio; BMI: body mass index; COPD: chronic obstructive pulmonary disease; ACEi: angiotensinconverting enzyme inhibitors; ARB: angiotensin II receptor blocker; $\mathrm{SpO}_{2}$ : peripheral oxygen saturation; CI: confidence interval. * OR values are adjusted for sex and age. OR $>1$ indicates that the characteristic is more frequent in COVID-19 group than in influenza group. Bold: subtitle. 


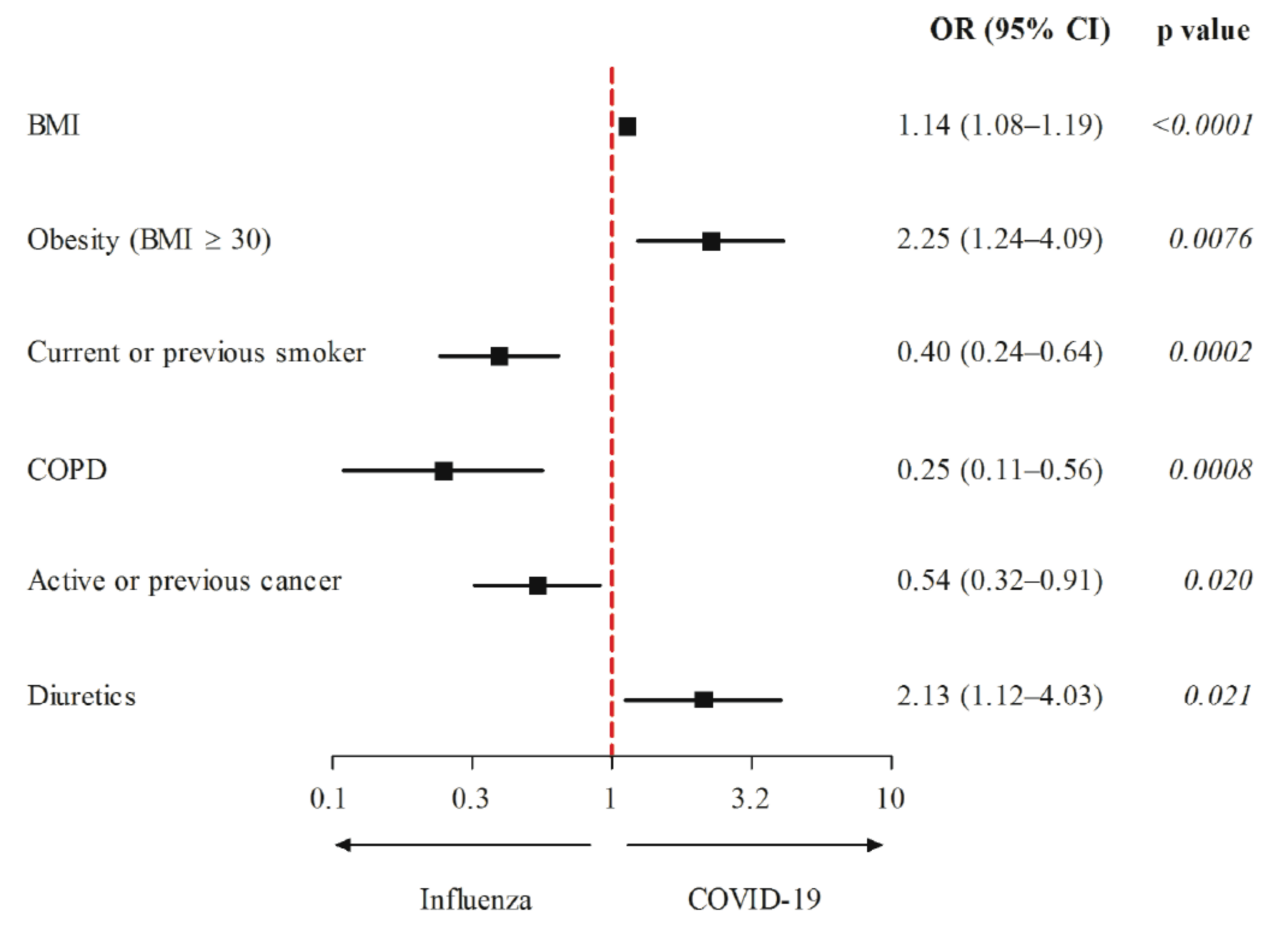

(A)

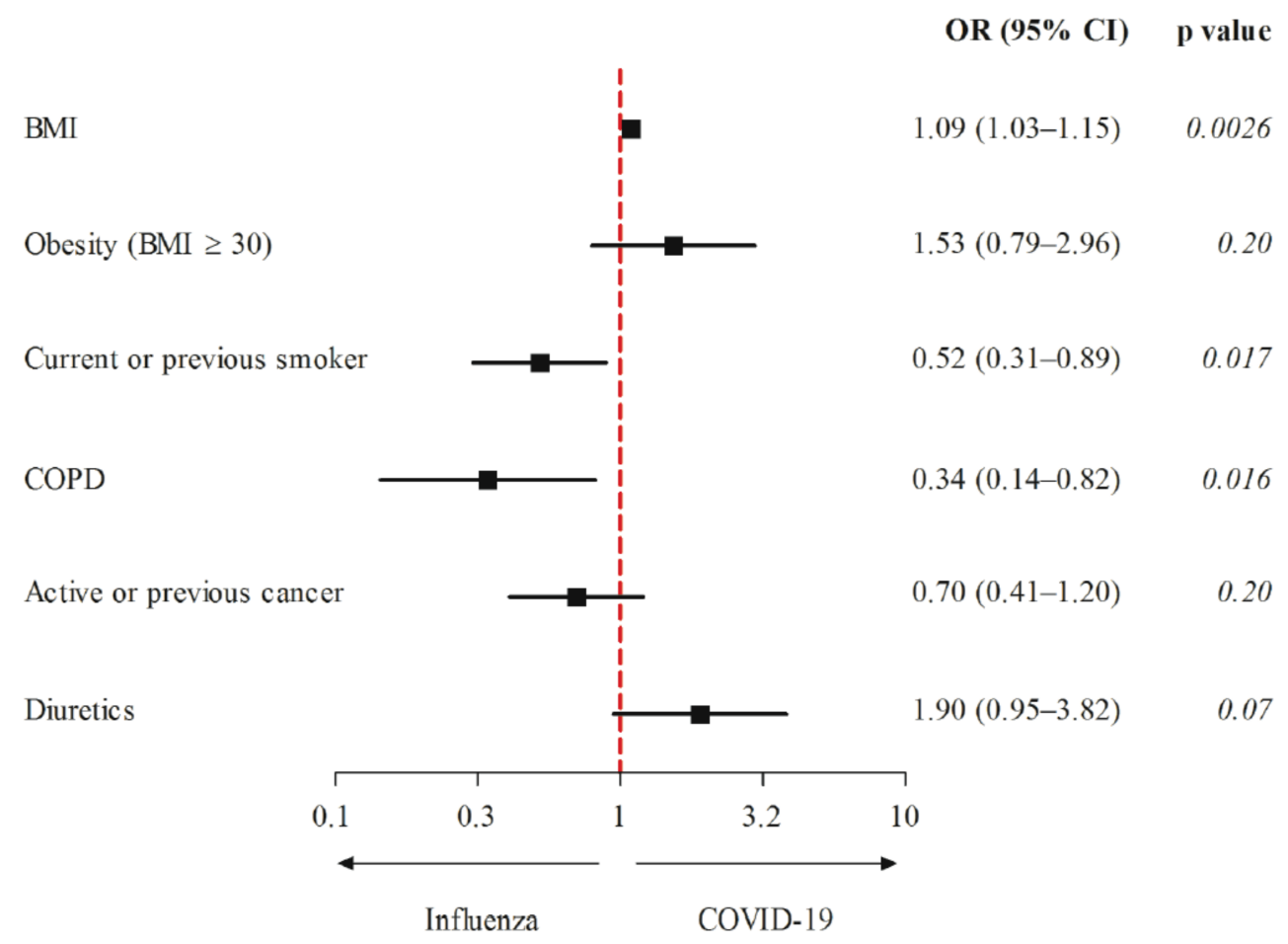

(B)

Figure 2. Representation of ORs between COVID-19 and influenza hospitalized patients. (A) ICU and non-ICU patients. (B) Non-ICU patients.

\section{Discussion}

This single-center analysis was performed on 253 initial COVID-19 patients admitted from 12 March 2020 to 1 April 2020, providing a picture of the first COVID-19 cases with severe and critical pneumonia as the SARS-CoV-2 epidemic expanded in France before the initiation of a lockdown on 16 March 2020. In this cohort, obese patients and those 
receiving medications for hypertension were found to be at a higher risk of critical and fatal COVID-19. These associations were significant after adjusting for age and sex. Our results highlight the typical profile of a severe or critical COVID-19 patient as a 65-year-old male with underlying metabolic syndrome. These characteristics do not seem to overlap with the classical pattern of viral respiratory infections as our data indicate that patients hospitalized at the same center for influenza pneumonia during the winters of 2017-2018 and 2018-2019 were significantly older with lower BMIs and with an equal distribution between male and female as well as having a higher proportion of underlying lung diseases as evidenced by the higher rates of COPD or reported smoking habits. This result is concordant with a higher tropism for the endothelium with SARS-CoV-2 as compared to influenza viruses [22]

In comparison with 153 patients with influenza pneumonia from 8 December 2017 to 17 December 2019 and hospitalized in the same hospital and thereby representing the same patients at risk, we confirm a recent study performed on a French national administrative database showing that the presentation of patients with COVID-19 and seasonal influenza requiring hospitalization differs significantly [18]. In our study, however, we only included an adult population whereas 8942 of the 45,819 patients $(19.5 \%)$ included in the national cohort were under the age of 18 , which may have influenced the associated comorbidities [18]. We also included patients hospitalized for more than $24 \mathrm{~h}$ to rule out asymptomatic or minor illness.

Previous case series have reported the association between obesity and COVID-19 severity $[3,4,6]$. Obesity was also found to be related to the severity of other respiratory infections including the H1N1 influenza [12]. However, our analysis of patients with influenza pneumonia admitted in our center indicates that this pattern is not classic to other viral respiratory diseases but rather suggests the specific predisposition of obese patients to severe COVID-19. Although this association is consistent with that reported in other communities, including China [23] and the United States [3], it has not been observed for SARS-CoV-1.

While pre-existing hypertension was previously thought to be a predisposing factor to COVID-19 [2,8,17], we failed to observe this association in our patients because the proportion of hypertensive patients was similar between COVID-19 and those with influenza cases and in line with the known prevalence of hypertension in this age category [24]. On the contrary, the association between pre-existing hypertension and the risk of shortterm, in-hospital mortality was consistent with that reported in China [25]. In our study, hypertension was the only factor independently associated with in-hospital death after considering all potential confounders including age and sex. Interestingly, hypertension was more frequently reported in patients with SARS-CoV-1 requiring ICU admission during the 2003 epidemic [26]. Our results demonstrate a characteristic link between COVID-19 and hypertension that may have practical implications. Almost all COVID-19 patients with hypertension were treated with antihypertensive medications upon admission (93.2\%) and received a median of two medications. In comparison, patients with influenza pneumonia received a median of only one antihypertensive medication despite being older. Thus, COVID-19 affected patients with a more advanced hypertension phenotype than those with influenza as evidenced by the pre-hospitalization prescription of more antihypertensive medications at a younger age as compared with patients with influenza. This observation indicates that a higher degree of previous and long-lasting vascular damage and endothelial dysfunction in hypertensive patients who are then affected by COVID-19 increases the potential risk of endothelial invasion by SARS-CoV-2, consistent with the association with COVID-19 severity [22]. Pre-hospitalization diuretic prescriptions were more common in patients with COVID-19 than in those with influenza pneumonia. The ongoing diuretic treatment at entry mainly comprised hydrochlorothiazide administered in combination with other antihypertensive therapies, reiterating the specific association between COVID-19 and hypertension and its treatments. These data also indicate the need for specific measures and increased surveillance of patients with cardiometabolic diseases in the context of the COVID-19 pandemic. 
Histories of chronic respiratory diseases were less significantly observed in patients with COVID-19 than in those with influenza respiratory infections, suggesting the protective role of immunomodulating therapies such as inhaled corticosteroids [27]. Dedicated studies in suitable animal models and in humans are warranted to confirm these hypotheses.

Our study has some limitations. As a single-center study, the total sample size is smaller than that in other studies. However, the different patient characteristics are compatible with those observed in the French population of same age and sex [24], indicating that our data are representative of an unselected group of French patients infected with SARS-CoV-2 during the first wave of the pandemic in 2020. It is also unknown whether the influence of cardiometabolic factors is different with novel SARS-CoV-2 variants.

\section{Conclusions}

Critical COVID-19 pneumonia is associated with sex (male) and obesity while inhospital mortality is associated with pre-existing hypertension independent of age and sex. The clinical factors favoring the incidence of COVID-19 do not overlap with those favoring influenza respiratory infections. Notably, cardiometabolic disorders differentially influenced the risk of presenting a severe COVID-19 or influenza pneumonia.

Author Contributions: J.-S.H., M.A., A.F., M.L. and G.C. designed the study, had full access to all of the data, and take the responsibility of data integrity and accuracy of the data analysis. J.S.H. drafted the paper with the help of A.F., M.L., M.A., H.P., G.C. and N.M.; H.P., M.A., G.C. and J.-S.H. performed all the analyses. S.C. and A.-S.J helped interpreting the analyses. J.-L.D., C.H., D.L., J.-B.A., B.C., F.B., O.S., B.P., C.C., A.G., A.N., T.M., S.-R.H., H.P., J.-B.C. and G.V. collected the data. All authors critically revised the manuscript for important intellectual content and gave final approval for the version to be published. All authors have read and agreed to the published version of the manuscript.

Funding: This study received no external funding.

Institutional Review Board Statement: The study was conducted according to the guidelines of the Declaration of Helsinki and approved by the institutional review board (IRB registration \#00011928, CERAPHP.5, authorization 2020-CVD-02) and declared to the European General Data Protection Regulation (20200410153717).

Informed Consent Statement: Patients included in the present study were all informed that their medical data could be used for research purpose, in accordance with the General Data Protection Regulation 2016/679.

Data Availability Statement: The data presented in this study are available on request from the corresponding author. The data are not publicly available due to privacy restrictions.

Conflicts of Interest: The authors declare no conflict of interest.

\section{References}

1. Guan, W.J.; Ni, Z.Y.; Hu, Y.; Liang, W.H.; Ou, C.Q.; He, J.X.; Liu, L.; Shan, H.; Lei, C.L.; Hui, D.S.C.; et al. Clinical Characteristics of Coronavirus Disease 2019 in China. N. Engl. J. Med. 2020, 382, 1708-1720. [CrossRef]

2. Zhou, F.; Yu, T.; Du, R.; Fan, G.; Liu, Y.; Liu, Z.; Xiang, J.; Wang, Y.; Song, B.; Gu, X.; et al. Clinical course and risk factors for mortality of adult inpatients with COVID-19 in Wuhan, China: A retrospective cohort study. Lancet 2020, 395, 1054-1062. [CrossRef]

3. Goyal, P.; Choi, J.J.; Pinheiro, C.L.; Schenck, J.E.; Chen, R.; Jabri, A.; Satlin, J.M.; Campion, T.R., Jr.; Nahid, M.; Ringel, B.J.; et al. Clinical Characteristics of Covid-19 in New York City. N. Engl. J. Med. 2020, 382, 2372-2374. [CrossRef]

4. Simonnet, A.; Chetboun, M.; Poissy, J.; Raverdy, V.; Noulette, J.; Duhamel, A.; Labreuche, J.; Mathieu, D.; Pattou, F.; Jourdain, M.; et al. High Prevalence of Obesity in Severe Acute Respiratory Syndrome Coronavirus-2 (SARS-CoV-2) Requiring Invasive Mechanical Ventilation. Obesity (Silver Spring) 2020, 28, 1195-1199. [CrossRef]

5. Petrilli, C.M.; Jones, S.A.; Yang, J.; Rajagopalan, H.; O’Donnell, L.; Chernyak, Y.; Tobin, K.A.; Cerfolio, R.J.; Francois, F.; Horwitz, L.I. Factors associated with hospital admission and critical illness among 5279 people with coronavirus disease 2019 in New York City: Prospective cohort study. BMJ 2020, 369, m1966. [CrossRef]

6. Czernichow, S.; Beeker, N.; Rives-Lange, C.; Guerot, E.; Diehl, J.L.; Katsahian, S.; Hulot, J.S.; Poghosyan, T.; Carette, C.; Jannot, A.S.; et al. Obesity Doubles Mortality in Patients Hospitalized for Severe Acute Respiratory Syndrome Coronavirus 2 in Paris Hospitals, France: A Cohort Study on 5795 Patients. Obesity (Silver Spring) 2020, 28, 2282-2289. [CrossRef] 
7. Wu, Z.; McGoogan, J.M. Characteristics of and Important Lessons From the Coronavirus Disease 2019 (COVID-19) Outbreak in China: Summary of a Report of 72314 Cases From the Chinese Center for Disease Control and Prevention. JAMA 2020, 323, 1239-1242. [CrossRef] [PubMed]

8. Xie, J.; Tong, Z.; Guan, X.; Du, B.; Qiu, H. Clinical Characteristics of Patients Who Died of Coronavirus Disease 2019 in China. JAMA Netw. Open 2020, 3, e205619. [CrossRef] [PubMed]

9. Huang, C.; Wang, Y.; Li, X.; Ren, L.; Zhao, J.; Hu, Y.; Zhang, L.; Fan, G.; Xu, J.; Gu, X.; et al. Clinical features of patients infected with 2019 novel coronavirus in Wuhan, China. Lancet 2020, 395, 497-506. [CrossRef]

10. Ayoub, C.; Murad, M.H. Population-based screening for vascular disease. Lancet 2017, 390, 2218-2220. [CrossRef]

11. Koivula, I.; Sten, M.; Makela, P.H. Risk factors for pneumonia in the elderly. Am. J. Med. 1994, 96, 313-320. [CrossRef]

12. Fezeu, L.; Julia, C.; Henegar, A.; Bitu, J.; Hu, F.B.; Grobbee, D.E.; Kengne, A.P.; Hercberg, S.; Czernichow, S. Obesity is associated with higher risk of intensive care unit admission and death in influenza A (H1N1) patients: A systematic review and meta-analysis. Obes Rev. 2011, 12, 653-659. [CrossRef]

13. Johnstone, J.; Loeb, M.; Teo, K.K.; Gao, P.; Dyal, L.; Liu, L.; Avezum, A.; Cardona-Munoz, E.; Sleight, P.; Fagard, R.; et al. Influenza vaccination and major adverse vascular events in high-risk patients. Circulation 2012, 126, 278-286. [CrossRef] [PubMed]

14. Henry, C.; Zaizafoun, M.; Stock, E.; Ghamande, S.; Arroliga, A.C.; White, H.D. Impact of angiotensin-converting enzyme inhibitors and statins on viral pneumonia. Proc. Bayl Univ Med. Cent. 2018, 31, 419-423. [CrossRef] [PubMed]

15. Soto, M.; Bang, S.I.; McCombs, J.; Rodgers, K.E. Renin Angiotensin system-modifying therapies are associated with improved pulmonary health. Clin. Diabetes Endocrinol. 2017, 3, 6. [CrossRef] [PubMed]

16. Chung, S.C.; Providencia, R.; Sofat, R. Association between Angiotensin Blockade and Incidence of Influenza in the United Kingdom. N. Engl. J. Med. 2020, 383, 397-400. [CrossRef]

17. Kreutz, R.; Algharably, E.A.E.; Azizi, M.; Dobrowolski, P.; Guzik, T.; Januszewicz, A.; Persu, A.; Prejbisz, A.; Riemer, T.G.; Wang, J.G.; et al. Hypertension, the renin-angiotensin system, and the risk of lower respiratory tract infections and lung injury: Implications for COVID-19. Cardiovasc. Res. 2020, 116, 1688-1699. [CrossRef]

18. Piroth, L.; Cottenet, J.; Mariet, A.S.; Bonniaud, P.; Blot, M.; Tubert-Bitter, P.; Quantin, C. Comparison of the characteristics, morbidity, and mortality of COVID-19 and seasonal influenza: A nationwide, population-based retrospective cohort study. Lancet Respir. Med. 2021, 9, 251-259. [CrossRef]

19. Petersen, E.; Koopmans, M.; Go, U.; Hamer, D.H.; Petrosillo, N.; Castelli, F.; Storgaard, M.; Al Khalili, S.; Simonsen, L. Comparing SARS-CoV-2 with SARS-CoV and influenza pandemics. Lancet Infect. Dis. 2020, 20, e238-e244. [CrossRef]

20. Zhao, W.; Zhong, Z.; Xie, X.; Yu, Q.; Liu, J. Relation Between Chest CT Findings and Clinical Conditions of Coronavirus Disease (COVID-19) Pneumonia: A Multicenter Study. AJR Am. J. Roentgenol. 2020, 214, 1072-1077. [CrossRef]

21. Force, A.D.T.; Ranieri, V.M.; Rubenfeld, G.D.; Thompson, B.T.; Ferguson, N.D.; Caldwell, E.; Fan, E.; Camporota, L.; Slutsky, A.S. Acute respiratory distress syndrome: The Berlin Definition. JAMA 2012, 307, 2526-2533.

22. Varga, Z.; Flammer, A.J.; Steiger, P.; Haberecker, M.; Andermatt, R.; Zinkernagel, A.S.; Mehra, M.R.; Schuepbach, R.A.; Ruschitzka, F.; Moch, H. Endothelial cell infection and endotheliitis in COVID-19. Lancet 2020, 395, 1417-1418. [CrossRef]

23. Zheng, K.I.; Gao, F.; Wang, X.B.; Sun, Q.F.; Pan, K.H.; Wang, T.Y.; Ma, H.L.; Chen, Y.P.; Liu, W.Y.; George, J.; et al. Letter to the Editor: Obesity as a risk factor for greater severity of COVID-19 in patients with metabolic associated fatty liver disease. Metabolism 2020, 108, 154244. [CrossRef] [PubMed]

24. Vallee, A.; Gabet, A.; Grave, C.; Sorbets, E.; Blacher, J.; Olie, V. Patterns of hypertension management in France in 2015: The ESTEBAN survey. J. Clin. Hypertens (Greenwich) 2020, 22, 663-672. [CrossRef] [PubMed]

25. Li, J.; Wang, X.; Chen, J.; Zhang, H.; Deng, A. Association of Renin-Angiotensin System Inhibitors with Severity or Risk of Death in Patients With Hypertension Hospitalized for Coronavirus Disease 2019 (COVID-19) Infection in Wuhan, China. JAMA Cardiol 2020, 5, 825-830. [CrossRef] [PubMed]

26. Lew, T.W.; Kwek, T.K.; Tai, D.; Earnest, A.; Loo, S.; Singh, K.; Kwan, K.M.; Chan, Y.; Yim, C.F.; Bek, S.L.; et al. Acute respiratory distress syndrome in critically ill patients with severe acute respiratory syndrome. JAMA 2003, 290, 374-380. [CrossRef] [PubMed]

27. Halpin, D.M.G.; Faner, R.; Sibila, O.; Badia, J.R.; Agusti, A. Do chronic respiratory diseases or their treatment affect the risk of SARS-CoV-2 infection? Lancet Respir Med. 2020, 8, 436-438. [CrossRef] 